\title{
Advances in Resist Materials for 193 nm Lithography
}

\author{
Murrae J. Bowden, Allen H. Gabor, Ognian Dimov, \\ Arturo N. Medina, Patrick Foster, Thomas Steinhäusler, John J. \\ Biafore, Gregory Spaziano, Sydney G. Slater, \\ Andrew J. Blakeney, Mark O. Neisser \\ Arch Chemicals. \\ 200 Massasoit Avenue, East Providence, RI 02914
}

\author{
Frank M. Houlihan, Ray A. Cirelli, Gary Dabbagh, Richard S. \\ Hutton, Ilya L. Rushkin, James R. Sweeney, Allen G. Timko, Om \\ Nalamasu, Elsa Reichmanis
}

Bell Laboratories, Lucent Technologies

600 Mountain Avenue

Murray Hill, NJ 07974

\begin{abstract}
The performance of a $193 \mathrm{~nm}$ single layer resist based on a norbornene-maleic anhydride matrix resin has been optimized through a series of statistical design experiments. The SDE demonstrated the importance of setting the PEB temperature above the SB temperature with optimum performance being observed at a SB of $150^{\circ} \mathrm{C}$ and a PEB of $160^{\circ} \mathrm{C}$. The lithographic performance of the resist was also strongly influenced by polymer composition, specifically acrylate loading and blocking level. Optimizing the composition of the polymer, gave resists with high etch resistance, square profiles and 0.130 micron dense line ultimate resolution in 0.5 micron thick films. The resist formulations are compatible with industry standard $0.262 \mathrm{~N}$ TMAH. During exposure the resist does not suffer from the outgassing of volatile species (less than $1 \mathrm{e} 12$ molecules $/ \mathrm{cm} 2 \mathrm{x} \mathrm{sec}$ ).

A new thermally curable undercoat for bi-layer application has also been developed whose optical properties have been optimized to reduce reflectivity at the desired wavelength. The reflectivity has been reduced by a factor of eight over an earlier UV-cured version.
\end{abstract}

Keywords: $193 \mathrm{~nm}$ single layer resists, $193 \mathrm{~nm}$ bilayer resists.

\section{Introduction}

Work on the development of $193 \mathrm{~nm}$ resist materials was initiated in several laboratories in the early 1990s in anticipation of the introduction of $193 \mathrm{~nm}$ lithography some 10-15 years hence assuming, of course, Moore's Law remained a valid premise. The subsequent publication of the various generations of lithography road maps by the Semiconductor Industry Association (SIA) served not only to validate the early predictions, but also to accelerate the rate of technology development as companies strove to gain competitive advantage by perfecting the next generation of technology ahead of the predicted dates of introduction.

Advances in the design and development of $193 \mathrm{~nm}$ lithography tools has resulted in the introduction of first generation of commercial 
$193 \mathrm{~nm}$ scanners 1 which are expected to be operational in the advanced technology development groups of leading edge chip manufacturers by the middle of 1999 . Hence there is a premium on the availability of robust, production-worthy resist materials and processes to enable introduction of $193 \mathrm{~nm}$ lithography into volume manufacturing early in the new millennium.

The challenges facing the resist chemist in the design of $193 \mathrm{~nm}$ resists have been well documented 2,3 . In particular, the need for high transparency coupled with acceptable plasma etch resistance is especially problematic. Chemists had learned how to manipulate the transparency of phenolic-based polymers such as novolak ( $\mathrm{g}$ and $\mathrm{i}-$ line lithography) and poly(hydroxystyrene) (248nm lithography) for acceptable imaging which enabled them to take advantage of the superior plasma etch resistance of these materials which derives from the aromatic ring. However, the inherently high absorption of phenolic-based materials at $193 \mathrm{~nm}$ resulting from the strong $\pi-\pi^{*}$ electronic transition in that spectral region precludes their use in $193 \mathrm{~nm}$ resist design necessitating a new approach.

It had been known that aliphatic methacrylate esters were relatively transparent to $193 \mathrm{~nm}$ radiation, but their poor plasma etch resistance precluded practical application in single layer resist application. The observation that alicyclic groups, which are quite transparent at $193 \mathrm{~nm}$, can confer a high degree of plasma etch resistance suggested that viable single layer resist systems could indeed be designed by incorporating such groups into the main polymer chain, or appended to the main chain, provided, of course, that all other resist properties such as photospeed, resolution, etc. could be met.

Researchers at Fujitsu4,5 reported good imaging performance in methacrylate esters containing pendant bi- and tri-alicyclic units such as adamantyl moieties. Many groups 6,7 have subsequently adopted this approach and some commercial prototypes based on acid-catalyzed cleavage of protected ester groups are believed based on the Fujitsu design.

The incorporation of alicyclic groups into the main polymer chain, typically as derivitized norbornyl polymers containing ester protecting groups, acidic groups and adhesion-promoting groups provided an alternative approach to achieving improved plasma etch resistance ${ }^{8}$. Norbornyl polymers can be polymerized by one of three synthetic pathways, viz., ring-opening methathesis polymerization, addition polymerization or radical polymerization. The former leads to double bonds in the backbone which absorb at $193 \mathrm{~nm}$ and hence must be reduced to remove the unsaturation. Radical addition is difficult to control whereas the metal-catalyzed addition method is reported to yield polymers with good hydrophobicity, high glass transition temperature, relatively high transparency at $193 \mathrm{~nm}$ and plasma etch resistance equal to or better than the current generation of DUV resists 9,10 . A potential drawback of the all-norbornyl systems relate to the use of Group VIII metallic catalysts, e.g., palladium compounds, which could be of concern from the standpoint of metal contamination.

An alternative approach was pioneered by researchers at Bell Laboratories 11,12 who took advantage of the facile free radical copolymerization of norbornene with maleic anhydride to make cyclic olefin alternating copolymers. While it might be expected that the maleic anhydride groups would lower plasma etch resistance, early results proved to the contrary and several research groups have reported very encouraging results with this system. The polar nature of the maleic anhydride group also has the effect of imparting hydrophilicity to the chain to offset the hydrophobic nature of the cyclic olefin monomer. Of the possible design variations considered, the Bell Labs researchers showed that a hybrid approach consisting of an initially baseinsoluble norbornyl-maleic anhydride-based polymer containing acidolytically cleavable t-butyl groups, a cholate dissolution inhibitor (DI) also functionalized with acidolytically cleavable groups and a photoacid generator (PAG) provided the best contrast and resolution capabilities.

Arch Chemicals and the Bell Labs group have been collaborating to optimize this system for commercial application.13,14 Specifically the resist system has five components, as shown in Figure 1.

These components include an alternating copolymer of norbornene and maleic anhydride that has acrylate monomers incorporated, a mixture of "mono" and "oligomeric" cholate based DIs, a photo-acid generator (PAG) and a base additive. The alicyclic nature of both the polymer and the DIs gives the resist good etch resistance 
both to polysilicon and oxide etch chemistries. The novel base additive shown has the advantage of photoimageablity, which can lead to faster photospeeds and higher contrast resists. Finally the PAG generates an acid which is non-volatile and does not have excess diffusion in the matrix of the resist. Clearly many variables must be considered in order to arrive at an optimum composition, formulation and process for this 5component system.
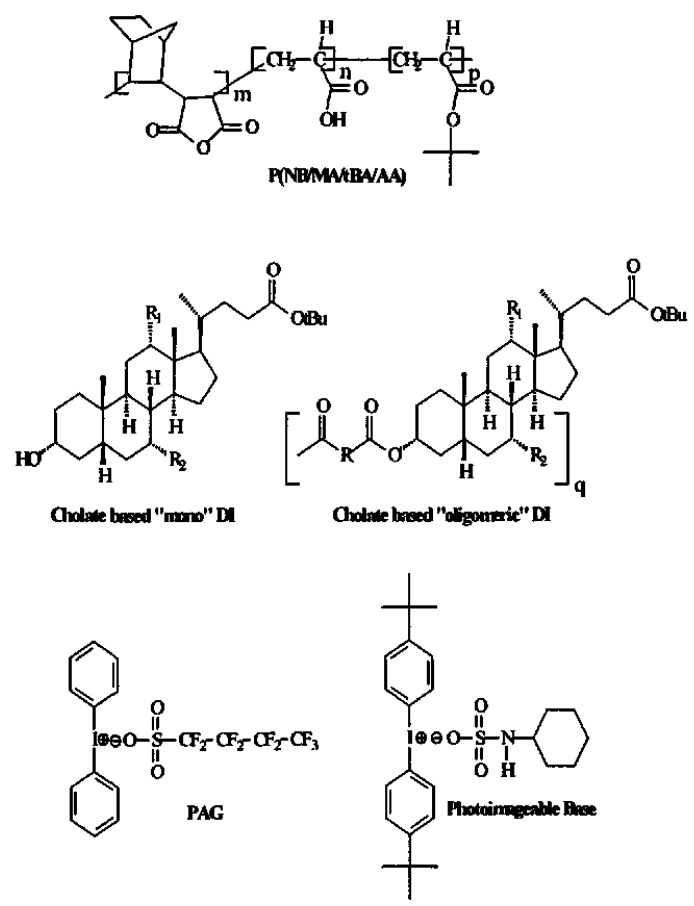

Figure 1. Generic structure of $193 \mathrm{~nm}$ single layer Resist.

An alternative approach that many feel offers improved resist performance and flexibility over single layer is based on a bi-layer approach. The advantage of utilizing a bilayer resist process lies in the ability to print high aspect ratio features as well as improved resolution and depth of focus as compared to other resist processes. Researchers at Arch Chemicals 15 recently reported results of a prototype bilayer system, which consists of a 2,500 $\AA$ methacrylate based imaging layer comprised of a terpolymer of tris (trimethyl silyloxy)-3methacryloxypropyl- silane, a property enhancing methacrylic acid ester, and a methacrylate monomer containing an $\alpha$-alkoxy ester acid labile group (Figure 2). on top of a $5000 \AA$ UV cured undercoat.

This system exhibited $0.13 \mu \mathrm{m}$ dense feature resolution and $0.12 \mu \mathrm{m}$ isolated line resolution when exposed at $193 \mathrm{~nm}$. However, it suffered from (1) sensitivity of the imaging layer to time delay between exposure and development, (2) variation in undercoat coating uniformity after the UV cure process (as much as $300 \AA$ ), (3) nonoptimized undercoat absorbing to efficiently minimize reflectivity, which resulted in a moderately high linewidth swing.<smiles>[R]OC(=O)C(CC(C)(C)C)(CC(C)(C)C)C(=O)OC([R7])O[Z]</smiles>

Figure 2. First generation imaging layer polymer

In the design of a second generation bilayer system, we determined that it would be necessary to change the composition of the undercoat in order to meet the target absorbance values. The role of the undercoat in a bilayer system is to act as a bottom antireflective coating as well as to provide sufficient etch resistance needed for pattern transfer to the substrate. The usual highly etch resistant phenyl based monomers are too highly absorbing to be the used as the backbone in a $193 \mathrm{~nm}$ resist. Therefore, more transparent materials, such as cyclic hydrocarbons, must be used when designing both the imaging layer and the undercoat layer.

In this paper, we present recent results on the application of response surface experimental design (statistical design) methods to optimize the many variables (composition, formulation and processing) associated with the 5-component single layer resist. We also present results on a new thermally cured undercoat for our bi-layer system which exhibits improved performance over the earlier version.

\section{RESULTS AND DISCUSSION}

\subsection{Single Layer Optimization}

\subsubsection{Formulation Statistical Design Experiments} with Version 1 Materials.

Each of the 5 components in the Arch/Bell Labs single layer resist formulation influences the lithographic performance of the resist and many have strong interactions between them. In designing the SDE, we chose to treat the polymer, mono DI, oligomeric DI and the PAG as mixture variables meaning the sum of the percentages of 
these four components must equal $100 \%$. Although, base is truly a mixture variable, it is added in such small amounts relative to the other components that it is easier to incorporate it into the SDE as the continuous variable PAG/base. For the formulation SDE, the ranges for the various components were set as follows; $1 / 2$ to 2 times the standard PAG amount, $1 / 3$ to 2 times the standard oligomeric DI amount, $1 / 3$ to 2 times the standard mono DI amount, and 12 to 25 for the PAG/base ratio. Twenty five unique trials were formulated and then lithographically evaluated for contrast, photospeed, depth of focus (DOF), profile quality and ultimate resolution. ECHIP® was then used to analyze the data and generate the response surfaces.

The cholate-based DIs are known to be powerful dissolution inhibitors. $7-10$ They also strongly influence the quality of the resist. Figure 3 illustrates how increasing the total DI loading (mono and oligomeric DI) initially increases the contrast of the resist very quickly. This can be seen by the large number of contour lines in the bottom half of the figure.

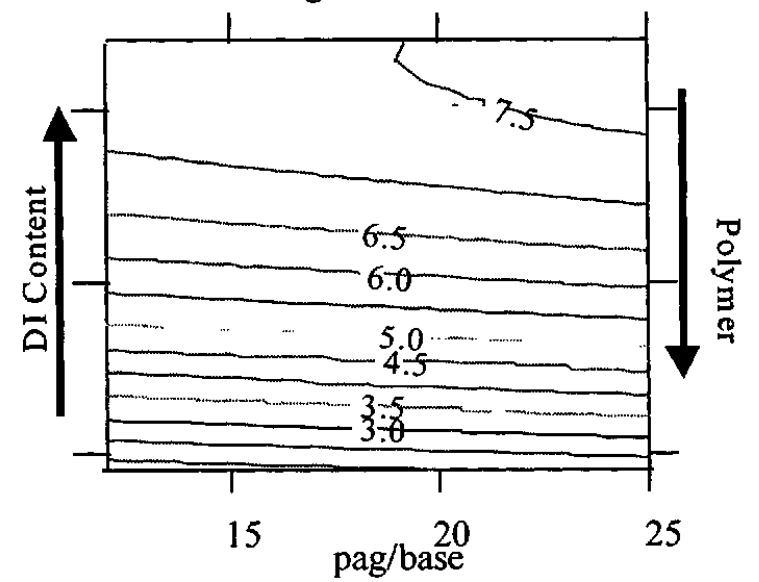

Figure 3. The effect of DI loading, polymer and $\mathrm{PAG} / \mathrm{base}$ ratio on the contrast of the resist.

It is important to note that as the DI loading increases the polymer loading is decreasing. The contrast reaches a plateau at some level of DI loading beyond which no additional improvement is seen. The best formulations for lithographic performance were found in the transition region between the sharply increasing contrast and the plateau.

While the DI and polymer loading strongly influence the contrast, the data in Figure 3 show that the corresponding dependence on PAG-tobase ratio is very small. However, photospeed and ultimate resolution are very much influenced as seen from the data in Figured 4 where increasing the PAG-to-base ratio from 12 to 25 reduced the E1:1 dose for the $190 \mathrm{~nm}$ equal line-spaces pairs (LS) from $17 \mathrm{~mJ} / \mathrm{cm}^{2}$ to $10 \mathrm{~mJ} / \mathrm{cm}^{2}$.

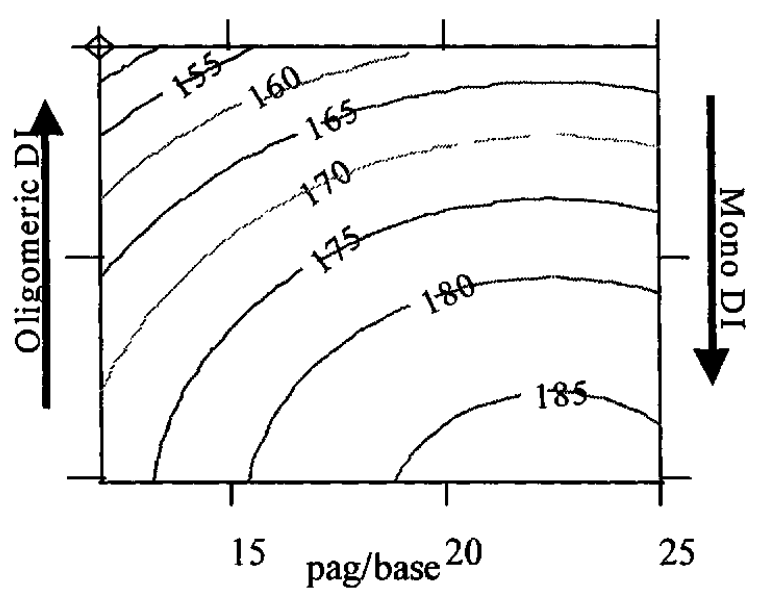

Figure 4. The effect of DI loading, polymer and PAG/base ratio on the $E 1: 1 \mathrm{dose}\left(\mathrm{mJ} / \mathrm{cm}^{2}\right)$ for 190 line space patterns.

The explanation for this behavior is that as the PAG-to-base ratio is increased (by lowering the amount of base in the formulation), more photogenerated-acid becomes available for catalyzing the cleavage of t-butyl ester groups of the polymer and DIs. The improvement in photospeed, however, is achieved at the expense of ultimate dense line resolution (for this paper, 'dense line' is equivalent to equal line and space features). Formulations with the lowest PAG-to-base ratio exhibited the best dense line resolution.

Dense line resolution is also affected by the ratio of oligomeric to mono DI. As shown in Figure 5, dense line resolution improves from 172 $\mathrm{nm}$ to $150 \mathrm{~nm}$ by increasing the oligomeric DI loading and decreasing mono DI loading. While the dense line ultimate resolution was affected by both oligomeric to mono DI ratio and the PAG-tobase ratio performance of the isolated line resist was only weakly dependent on the PAG-to-base ratio and showed no dependency on the oligomeric to mono DI ratio (Figure 6).

The stronger dependence of dense line resolution compared with isolated line resolution on base loading is not surprising since the base additive helps control the diffusion of the photogenerated-acid which is very important for dense line resists where excess diffusion can decrease the resolution. However, the isolated line resist may actually benefit from additional acid diffusion. 


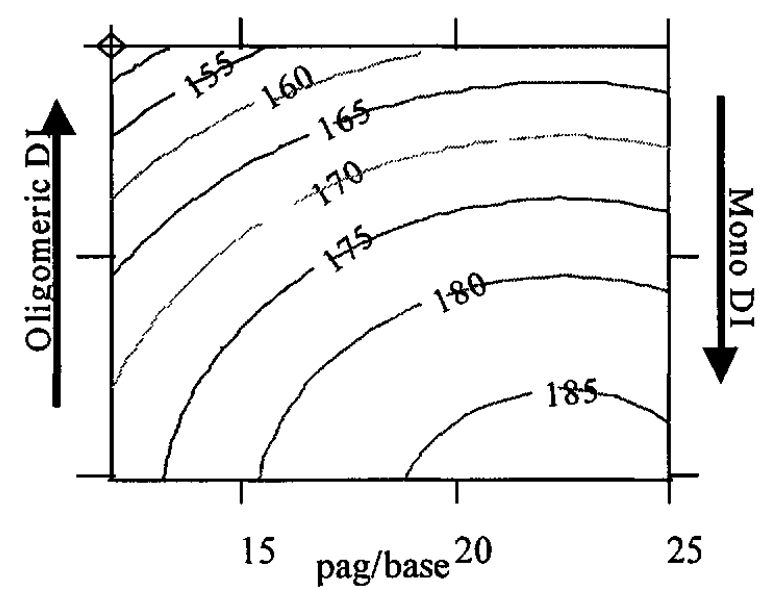

Figure 5. The effect of oligomeric DI, mono DI and PAG/base ratio on the ultimate dense line resolution $(\mathrm{nm})$.

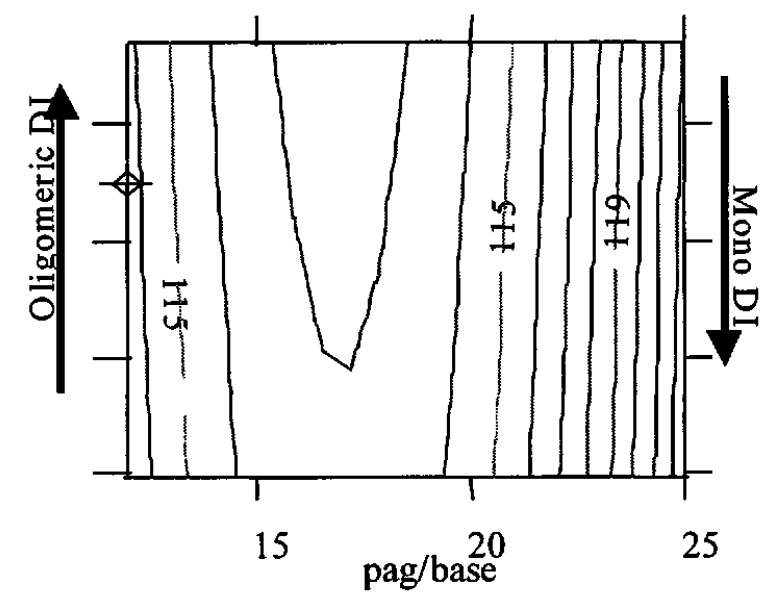

Figure 6. The effect of oligomeric DI, mono DI and PAG/base ratio on the ultimate isolated line resolution $(\mathrm{nm})$.

Comparing Figures 5 and 6, it is also evident that the optimal formulation for isolated lines is different than that for dense lines necessitating one formulation for isolated lines and another for dense lines.

The rest of this paper will focus primarily on efforts to further optimize the dense line resist, which included processing and polymer composition SDEs. Preliminary results on the lithographic performance of an isolated line formulation will also be discussed.

\subsubsection{Processing Statistical Design Experiments with Version 1 Dense Resist.}

Ranges for the SB and PEB temperature were set between 140 and $155^{\circ} \mathrm{C}$ and the SB and PEB time from 50 to 100 seconds. Nineteen unique sets of SB and PEB conditions were lithographically evaluated in terms of contrast, photospeed, DOF, profile quality and ultimate resolution. ECHIP® was then used to analyze the data and generate the response surfaces.

One of the main findings of the SDE was the importance of setting the PEB temperature 10 to $15^{\circ} \mathrm{C}$ above the SB temperature. Figure 7 demonstrates that even for dense line resolution

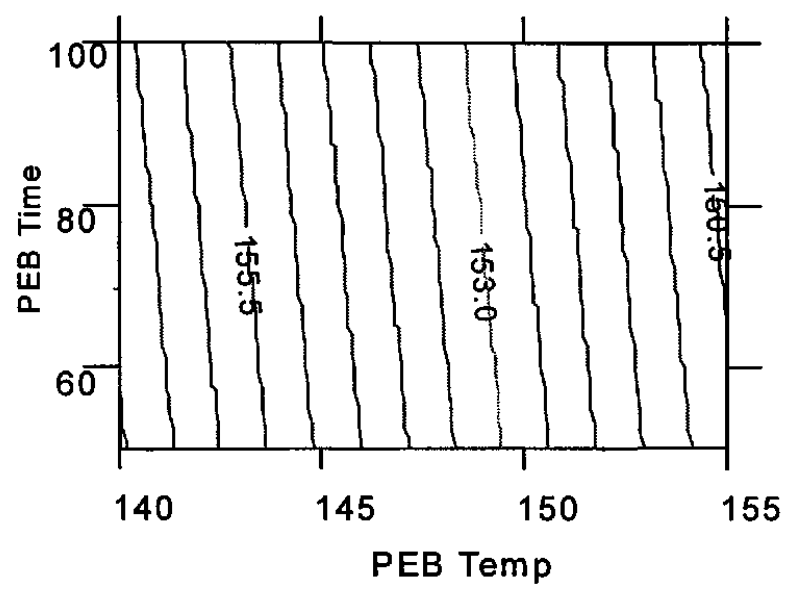

Figure 7. The effect PEB temperature and time on the ultimate dense line resolution (nm). SB temperature $: 140^{\circ} \mathrm{C}$; SB time: $90 \mathrm{~s}$.

(which is the least sensitive to PEB temperature), the ultimate LS resolution is improved by increasing the PEB temperature above the SB temperature. Other lithographic properties evaluated, viz., DOF, wall profile and linearity of the dense resist, showed even stronger improvement. The results for DOF are illustrated in Figure 8 (note that the DOF analyzed was the

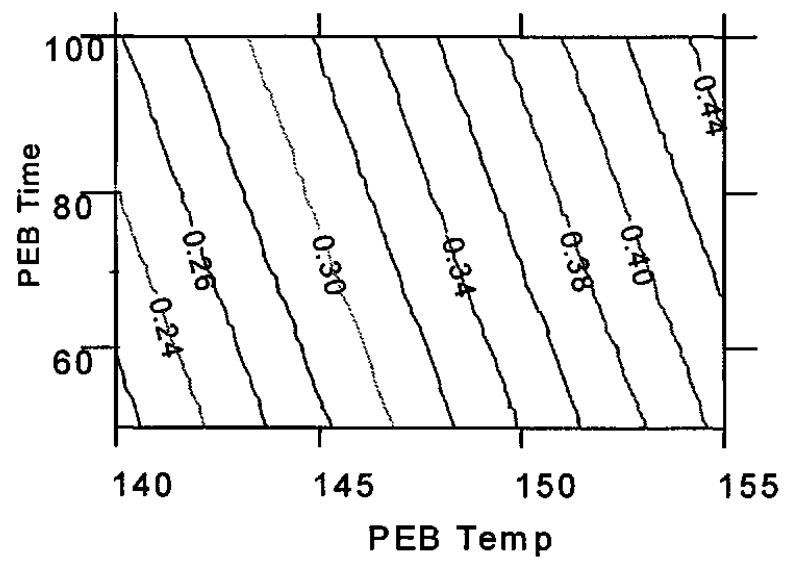

Figure 8. The effect PEB temperature and time on the DOF (microns). The DOF analyzed was the average of the DOF for the 160 and $180 \mathrm{~nm} \mathrm{LS}$.

average of the DOF for the 160 and $180 \mathrm{~nm} \mathrm{~L} / \mathrm{S}$ patterns). Increasing the PEB temperature $15^{\circ} \mathrm{C}$ above the SB temperature improves the DOF by 
$160 \mathrm{~nm}$. The DOF could be even further extended by a full $200 \mathrm{~nm}$ by increasing the PEB time.

\subsubsection{Discussion of Processing SDE Results.}

The improvement in lithographic performance obtained by setting PEB temperature above the SB temperature is contrary to what has been reported with ESCAP-type systems where it is thought that minimizing acid diffusion requires PEB temperatures lower than the SB temperature. Part of the difference may be attributed to the intrinsically lower temperatures required to deblock the $t$-butyl ester group in ESCAP polymers (which contain polar phenolic groups) as opposed to cholate-based DIs. For example, the tbutyl protecting groups on the cholate based DIs start to deblock at $250^{\circ} \mathrm{C}$ with no acid present (determined by TGA). This is in contrast to $\mathrm{P}(\mathrm{NB} / \mathrm{MA} / \mathrm{tBA} / \mathrm{AA})$ which starts to deblock at $200^{\circ} \mathrm{C}$ and poly(t-butylacrylate-co-hydroxystyrene) which starts to deblock at $183^{\circ} \mathrm{C}$ when no acid is present. Thus, while ESCAP type systems based on $t$-butyl acrylate typically require a $\mathrm{PEB}$ of $135^{\circ} \mathrm{C}, \mathrm{P}(\mathrm{NB} / \mathrm{MA} / \mathrm{tBA} / \mathrm{AA})$ formulated with cholate based DIs require a PEB of $155-160^{\circ} \mathrm{C}$ for optimal performance. Also, by having the SB temperature lower than the PEB temperature, we increase the diffusion of the photo-generated-acid and allow each acid molecule to come in contact with and deprotect additional t-butyl protecting groups.

\subsubsection{Effect of Polymer Composition Lithographic Dense Line Performance.}

Polymer composition has a major influence on the lithographic performance. Since norbornene and maleic anhydride copolymerize in an alternating fashion we can describe the polymer composition in terms of the percentage of monomer units that are acrylate and the blocking level (the ratio of the moles of tBA to the sum of tBA and AA). Figure 9 illustrates the effect of acrylate content and blocking level on the photospeed (Eo) of the resist. As expected, photospeed decreases with decreasing amount of acrylate, and with increasing blocking level. For a given acrylate percentage, the higher the blocking level the larger will be the number of t-butyl groups that need to be cleaved through acidolysis for the polymer to gain solubility in the aqueous base. That, in turn, requires higher acid concentrations and consequently a higher dose.

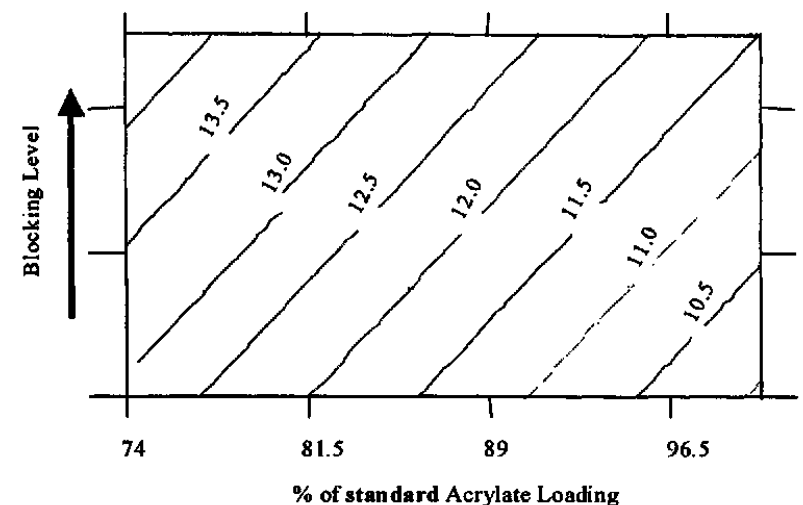

Figure 9. The effect of blocking level and acrylate loading on the photospeed $\left(E_{0} \mathrm{~mJ} / \mathrm{cm}^{2}\right.$ of the resist.

Although the photospeed decreases with decreasing acrylate content, many other lithographic properties improve. Figures 10-12 show the effect on of blocking level and acrylate loading on profile quality and linearity. All the SEMs were taken at the E1:1 dose for $160 \mathrm{~nm}$ dense features. Figure 10 shows the lithographic results for the polymer with the highest acrylate content and lowest blocking level. The profiles are rounded and linearity is poor (the $150 \mathrm{~nm}$ LS have residue in the spaces). Keeping the same acrylate content, but increasing the blocking level results in profiles that are less rounded and the $150 \mathrm{~nm} \mathrm{LS}$ are open (Figure 11). Square profiles are observed by lowering total acrylate content but keeping the blocking level relatively high (Figure 12). and the $145 \mathrm{~nm} \mathrm{~L} / \mathrm{S}$ are open. These results demonstrate that decreasing the acrylate content and increasing the blocking level can dramatically improve the performance of the resist. The same resist has an ultimate resolution of $130 \mathrm{~nm}$.

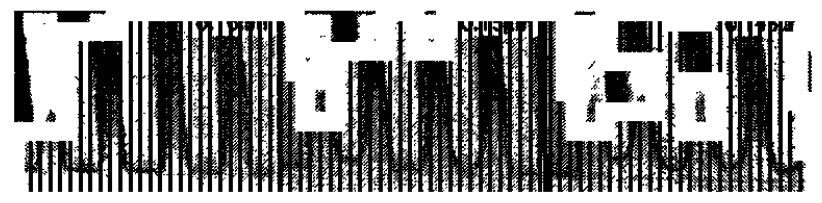

Figure 10: Linearity series on silicon for the polymer with the highest acrylate content and lowest blocking level. Emax: $511 \mathrm{~nm}$; Exposure: $22 \mathrm{~mJ} / \mathrm{cm}^{2}$; Develop:0.262 NTMAH/24" (0.6 NA, $\sigma=0.7)$

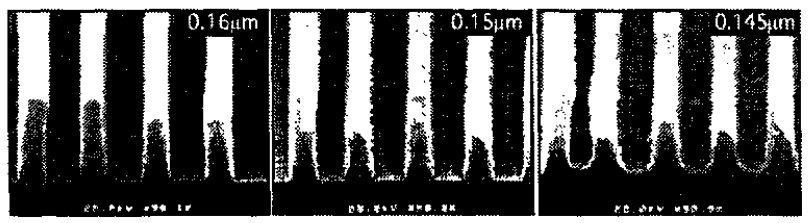

Figure 11: Linearity series on silicon for the polymer with the highest acrylate content and highest blocking level; Emax: $511 \mathrm{~nm}$; Exposure: $25.6 \mathrm{~mJ} / \mathrm{cm}^{2}$; Develop:0.262 NTMAH/24" (0.6 NA, $\sigma=0.7)$ 


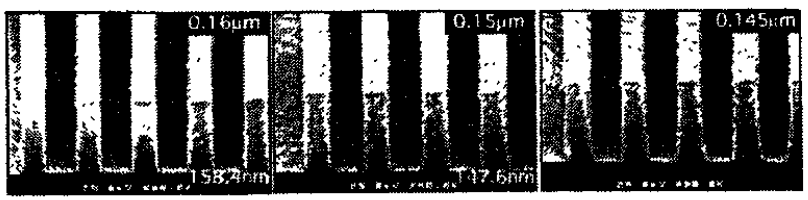

Figure 12: Linearity series on silicon for the polymer with the lowest acrylate content and highest blocking level. Emax: $511 \mathrm{~nm}$; Exposure:32.7 $\mathrm{mJ} / \mathrm{cm}^{2}$; Develop: 0.262 N TMAH/24" (0.6 NA, $\sigma=0.7)$

\subsubsection{Dense Line Performance on Inorganic $A R C$ with Binary and Phase Shift Masks (PSM).}

Figure 13 demonstrates the performance of the resist on inorganic ARC. The resist performs well on inorganic ARC due to its high transparency at $193 \mathrm{~nm} \quad\left[\mathrm{k}(193 \mathrm{~nm})=1.55 \times 10^{-2}\right]$. When an alternating aperture PSM is used, the resist can print $110 \mathrm{~nm}$ dense features on inorganic ARC with 0.3 microns of DOF (Figure 14).

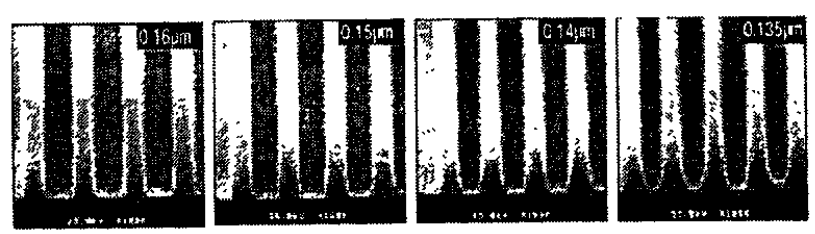

Figure 13: Linearity series on inorganic ARC for the polymer with the lowest acrylate content and highest blocking level. Emax: $511 \mathrm{~nm}$; Exposure: $34.8 \mathrm{~mJ} / \mathrm{cm}^{2}$; Develop:0.262 NTMAH/24" (0.6 NA, $\sigma=0.7)$

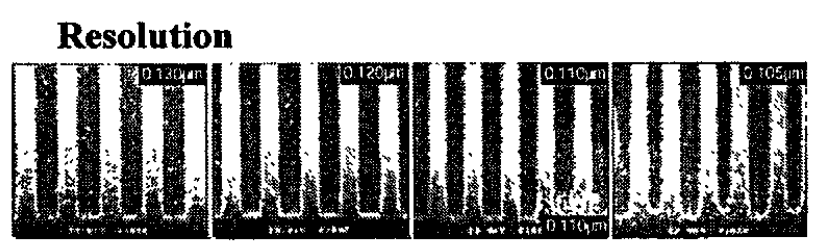

Depth of Focus 0.11 $\mu \mathrm{m}$

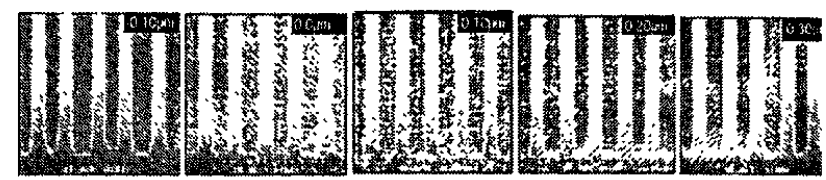

Figure 14: Linearity series and DOF of $110 \mathrm{~nm}$ dense features on inorganic ARC for the polymer with the lowest acrylate content and highest blocking level. The resist is $394 \mathrm{~nm}$ thick, exposed with $28.75 \mathrm{~mJ} / \mathrm{cm}^{2}$ and developed for 24 seconds using $0.262 \mathrm{~N} \mathrm{TMAH}(0.6$ NA, $\sigma=0.3$, PSM).

\subsubsection{Isolated Line Performance on Inorganic $A R C$ with Binary Mask.}

We followed a similar process, as that described in sections 2.2 and 2.4 , to improve the lithographic performance of our isolated line resist. After optimization, the isolated line resist was capable of imaging $110 \mathrm{~nm}$ isolated line features with 0.3 microns of DOF with standard optics and a binary mask (Figure 15). The resist has excellent photospeed (energy to size the $110 \mathrm{~nm}$ features is less than $15 \mathrm{~mJ} / \mathrm{cm} 2$ ) and operates well on inorganic ARC.

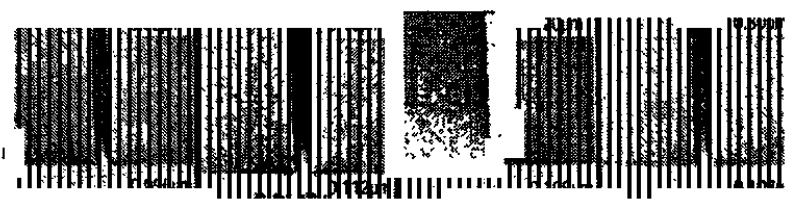

Figure 15: DOF of $110 \mathrm{~nm}$ isolated line features (30 nm mask bias) on inorganic ARC with the optimized isolated line resist. The resist is $339 \mathrm{~nm}$ thick, exposed with $14.6 \mathrm{~mJ} / \mathrm{cm}^{2}$ and developed for 12 seconds using $0.262 \mathrm{~N}$ TMAH ( $0.6 \mathrm{NA}, \sigma=0.7$, binary mask).

\subsection{Bi-layer Undercoat Improvement}

\subsubsection{First Generation Bilayer Resist System}

The undercoat in Arch Chemical's first generation resist system consists of a styrene copolymer and a photoactive crosslinker. UV curing crosslinks the undercoat matrix giving an undercoat layer which does not intermix with the imaging layer. Figure 16 shows images generated at $24.5 \mathrm{~mJ} / \mathrm{cm}^{2}$ in a $0.25 \mu \mathrm{m}$-thick imaging layer on a $0.45 \mu \mathrm{m}$ thick UV-cured undercoat. Resolution down to $0.125 \mu \mathrm{m}$ is observed and the spaces between the lines are nicely cleared out.
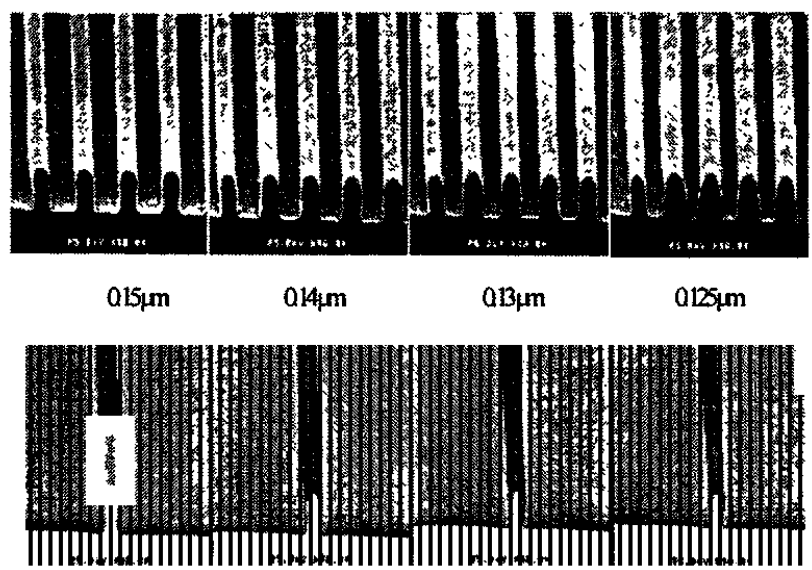

Figure 16: Dense and isolated line resolution on UVCured undercoat. Binary reticle, conventional illumination, $1: 1 \& 1: 8$ pitch.

However, the reflectivity of this system tends to be high $(4 \%)$ as seen in the simulated plot of 
reflectivity as a function of film thickness (Figure 17). The $\mathrm{k}$ value is between 0.6 and 0.7 .

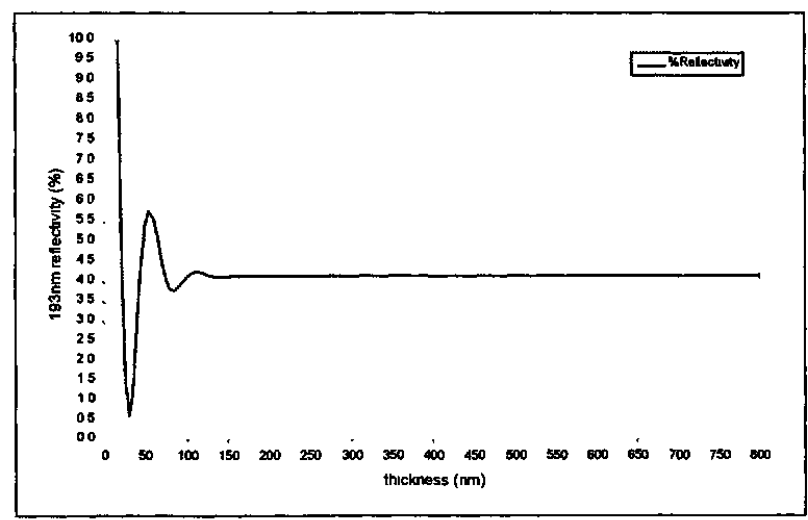

Figure 17: Simulated Reflectivity of UV-cured undercoat as a function of film thickness. Simulated using Prolith 5.0, $\mathrm{n}=1.70, \mathrm{k}=0.72$.

In addition to high reflectivity, the coatings were not always completely uniform after the UV cure process. Thermal curing was felt would give a more uniform cure and in addition be more compatible with current track capability.

\subsection{2 $193 \mathrm{~nm}$ Thermally Cured Undercoat}

Simulations using Prolith 5.0 showed the target $k$ value for the undercoat would need to be between 0.2 to 0.3 . Figure 18 shows the reflectivity of our new thermally cured undercoat at $193 \mathrm{~nm}$. As can be seen by comparison to the UV cured system, the reflectivity of the thermally cured undercoat has decreased from $4 \%$ to $0.5 \%$. The process conditions for the new thermally cured undercoat (TCU) are fairly broad. with cure temperature ranging from $150-250^{\circ} \mathrm{C}$, and cure time ranging from $45-180 \mathrm{sec}$.

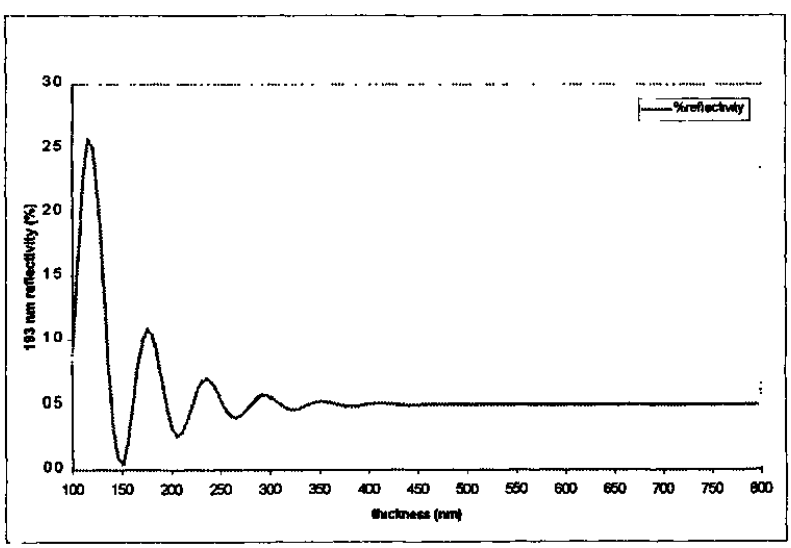

Figure 18: Simulated Reflectivity of $193 \mathrm{~nm}$ thermally cured undercoat as a function of film thickness. Simulated using Prolith 5.0, $\mathrm{n}=1.66, \mathrm{k}=0.26$
Figure 19 shows both dense and isolated line resolution for the first generation imaging layer on the new thermally cured undercoat.

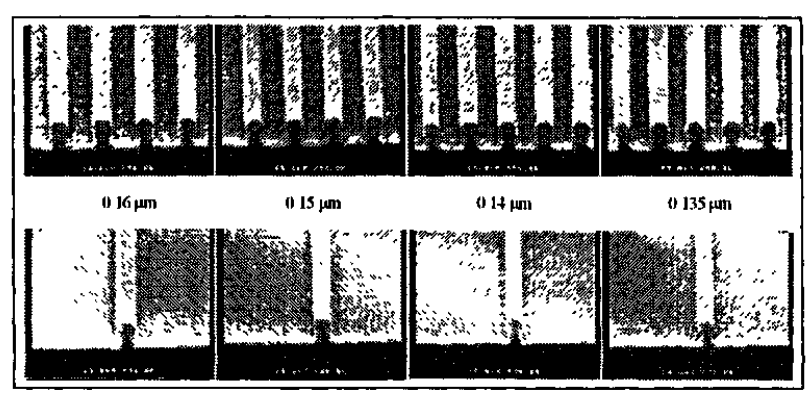

Figure 19: Dense and isolated line resolution on thermally cured undercoat. Binary reticle, conventional illumination, $1: 1 \& 1: 8$ pitch.

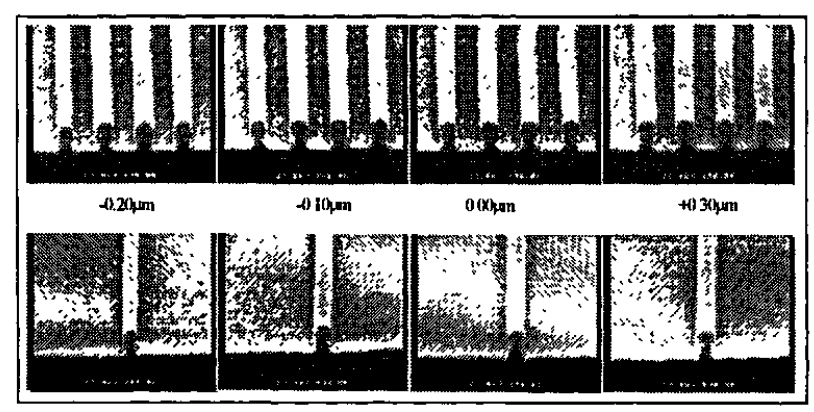

Figure 20: $0.15 \mu \mathrm{m}$ dense and isolated line depth of focus on thermally cured undercoat Binary reticle, conventional illumination, $1: 1 \& 1: 8$ pitch.

By comparison to Figure 16, the dense lines are resolved down to $0.135 \mu \mathrm{m}$ for the first generation imaging layer on TCU, which is comparable to the first generation imaging layer on UV cured undercoat. Likewise, the isolated lines show similar performance on thermally cured and UV-cured undercoats. undercoat. Figure 20 shows a $0.5 \mu \mathrm{m}$ depth of focus for $0.15 \mu \mathrm{m}$ dense and isolated line on the new $193 \mathrm{~nm}$ thermally cured undercoat.

\section{CONCLUSION}

Statistical design has been used to developed isolated and dense line $193 \mathrm{~nm}$ single layer resist formulations. Both resists perform well on many substrates including inorganic ARC. They exhibit exposure latitude for their target features $(160 \mathrm{~nm}$ for dense and $110 \mathrm{~nm}$ for isolated) greater than $10 \%$ with a binary mask. The isolated line resist meets our photospeed target (less than $15 \mathrm{~mJ} / \mathrm{cm}^{2}$ ). However, the dense line resist requires further improvement. With their inherent high oxide and polysilicon etch resistance, these resists are 
extremely promising candidates for use in real device fabrication.

A new thermally-cured undercoat for $193 \mathrm{~nm}$ bi-layer lithography has been developed whose optical properties can be varied according to the desired application. Initial evaluation of the lithographic performance of our first generation imaging layer on the new thermally cured undercoats shows performance comparable to the earlier UV-cured version with the added advantage of better film uniformity and compatibility with track processing.

\section{EXPERIMENTAL}

\subsection{Lithographic Processing for single layer resist}

Resists were formulated as described previously.10(f) and processed on an 8800 series SVG track. The thickness of the resist was measured using either a Nanospec AFT thickness gauge or a 2600 DUV Thermawave. All exposures were done using an ISI 9300/0.60 NA $\mathrm{ArF}$ excimer laser stepper. Unless otherwise stated, exposures were done using a binary mask, with a NA of 0.6 and $\sigma$ of 0.7 . Inorganic ARC wafers were prepared by depositing quarter wavelength tuned siliconoxynitride $(300 \AA)$ passivated with $100 \AA$ of silicon oxide using an Applied Materials Precision 5000 CVD platform. Silicon and the inorganic ARC wafers were HMDS primed for 300 seconds at $130^{\circ} \mathrm{C}$ in a YES oven. For the isolated line resist, unless otherwise stated, the soft bake (SB) condition was $150^{\circ} \mathrm{C}$ for $60 \mathrm{~s}$, the post exposure bake (PEB) condition was $160^{\circ} \mathrm{C}$ for $90 \mathrm{~s}$ and the development consisted of an $8 \mathrm{~s}$ dispense and a $12 \mathrm{~s}$ puddle using Arch Chemicals OPD262 (0.262 N TMAH) developer followed by a $30 \mathrm{~s}$ DI water rinse. For the dense line resist, unless otherwise stated, the soft bake (SB) condition was $140^{\circ} \mathrm{C}$ for $90 \mathrm{~s}$, the post exposure bake (PEB) condition was $155^{\circ} \mathrm{C}$ for $90 \mathrm{~s}$ and the development consisted of an $8 \mathrm{~s}$ dispense and a $24 \mathrm{~s}$ puddle using OPD262 (0.262 N TMAH) developer followed by a $30 \mathrm{~s}$ DI water rinse.

\subsection{Contrast Measurements}

Seventy two $1.5 \times 1.5 \mathrm{~mm}$ open frames were printed with increasing dose. Depending on the photospeed either 0.1 or $0.2 \mathrm{~mJ} / \mathrm{cm} 2$ increments were used. After development the thickness of each frame was measured. Contrast was calculated by fitting the best line (least squares) through the data in the transition region.

\subsection{Statistical Design}

ECHIP $\otimes$, a response surface experimental design software package, was used to design the statistical experiments. Usually quadratic designs were used. Depending on the number of variables being examined, anywhere from 10 to 32 unique trials were run. To eliminate day to day variability, all trials for one response were run on the same day. Thus, for the larger experiments, Eo/contrast wafers were run on one day while FEM (focus/exposure matrices) wafers were run on another day, since measurements on each set of wafers was independent.

\subsection{Bi-layer Processing}

The resist was processed using a combination of $90-110^{\circ} \mathrm{C} / 60 \mathrm{sec}$ post apply bake and a $90-100^{\circ} \mathrm{C} / 60 \mathrm{sec}$ post exposure bake. The resist was developed for $30 \mathrm{sec}$ in $0.262 \mathrm{~N}$ TMAH developer, rinsed and dried. Exposures were carried out using a $0.6 \mathrm{NA} 193 \mathrm{~nm}$ Microstepper.

\section{ACKNOWLEDGMENTS}

We wish to thank Roxanne Williams, and Michael Marconi for their excellent SEM work. We also wish to thank Jim Davidson, Woody Scott, Dennis Hottel, Rick Roberts, Bill Ashcraft, Ashok Reddy, Lee Whelan, Mike Sims and Craig Foster for their capable "scale-up" of all the materials used in our $193 \mathrm{~nm}$ single and bi-layer layer resists. We also wish to thank Sanjay Malik, Ed Fitzgerald, Walter Walbrick, Larry Ferreira, Bernie Beauchemin, Ed Fitzgerald, Bruce Buteau, Plamen Tzviatkov, Veerle Van Driessche and Steve Hansen of Arch Chemicals, Pat Watson of Lucent, Kim Dean of SEMATECH and John Hutchinson of Intel for their helpful discussions..

\section{REFERENCES}

1. I. Pollers, P. Jaenen, F. Van Roey, A. M. Goethels, G. Davies, B. Heskamp. H. Bakker, E. McCoo, J. Mulkens, J. Stroeldraijer, J. Sytsma, W. Van der Vleuten, B. Vleeming, P. Tzviatkov, V. Van Driessche and S. Slater, Proceedings, Microlith. Symp., Interface'98, 179, (1998).

2. H. Ito, J. Photopolymer Science and Technology, 11(3), 379 (1998).

3. R. D. Allen, J. Opitz, C. E. Larson, T. I. Wallow, and D. C. Hofer, Microlithography World., 8(1), 5 (1999).

4. Y. Kaimoto, K. Nozaki, S. Takechi, N. Abe, Proceedings SPIE, 1672, 66 (1992). 
5. S. Takechi, Y. Kaimoto, K. Nozaki, N. Abe, J. Photopolymer Science and technology, 5, 439 (1992).

6. R. D. Allen, G. M. Wallraff, R. A. DiPietro, D. C. Hofer, and R. R. Kunz., J. Photopolymer Science and technology, 7, 507 (1994).

7. K. Nakano, K. Maeda, S. Iwasa, T. Ohfuji, and E. Hasegawa, Proceedings SPIE, 2438422 (1995).

8. U. Okoroanyaanwu, T. Shimokawa, D. Medeiros, C. G. Willson, J. D. Byers, J. N. Quinshang, J. M. J. Frechet and R. D. Allen, Proceedings, SPIE, 304992 (1997).

9. R. D. Allen, J. Opitz, T. I. Wallow, R. A. DiPietro, D. C. Hofer, S. Jayaraman, K. A. Hullihan, L. F. Rhodes, B. L. Goodall and R. A. Shick, Proceedings, SPIE, 3333, 463

10. J. Opitz, R. D. Allen, T. I. Wallow, G. M. Wallraff, and D. C. Hofer, Proceedings SPIE, 3333, 571, 1998.
11. T. I. Wallow, F. M. Houlihan, O. Nalamasu, E. A. Chandross, T. X. Neenan and E. Reichmanis, Proceedings SPIE, 2724355 (1996).

12. F. M. Houlihan, T. I. Wallow, A. Timko, E. Neria, B. Hutton, R. Cirelli, O. Nalamasu and E. Reichmanis, Proceedings SPIE, 3049, 84 (1987).

13. F.M. Houlihan, J.M. Kometani, A.G. Timko, R.S. Timko, RA. Cirelli, E. Reichmanis, O. Nalamasu, A. H. Gabor, A. N. Medina, J. J. Biafore, S. G. Slater J. Photopolym. Sci. Technol., 11(3), 419, (1998).

14. F.M. Houlihan, J.M. Kometani, A.G. Timko, R.S. Timko, RA. Cirelli, E. Reichmanis, O. Nalamasu, A. H. Gabor, A. N. Medina, J. J. Biafore, S. G. Slater Proceedings SPIE, 3333, 73, (1998).

15. T. Steinhausler, A. H. Gabor, D. White, A. J. Blakeney, D. R. Stark, D. A. Miller, G. K. Rich, V. L. Graffenberg, K. R. Dean, SPIE 1998, 3333, 122 